\title{
Suzanne Y. O'Reilly and William L. Griffin
}

\author{
Jeff W. Harris ${ }^{1} \cdot$ Sonja Aulbach ${ }^{2}$ \\ (C) Springer-Verlag GmbH Austria, part of Springer Nature 2018
}

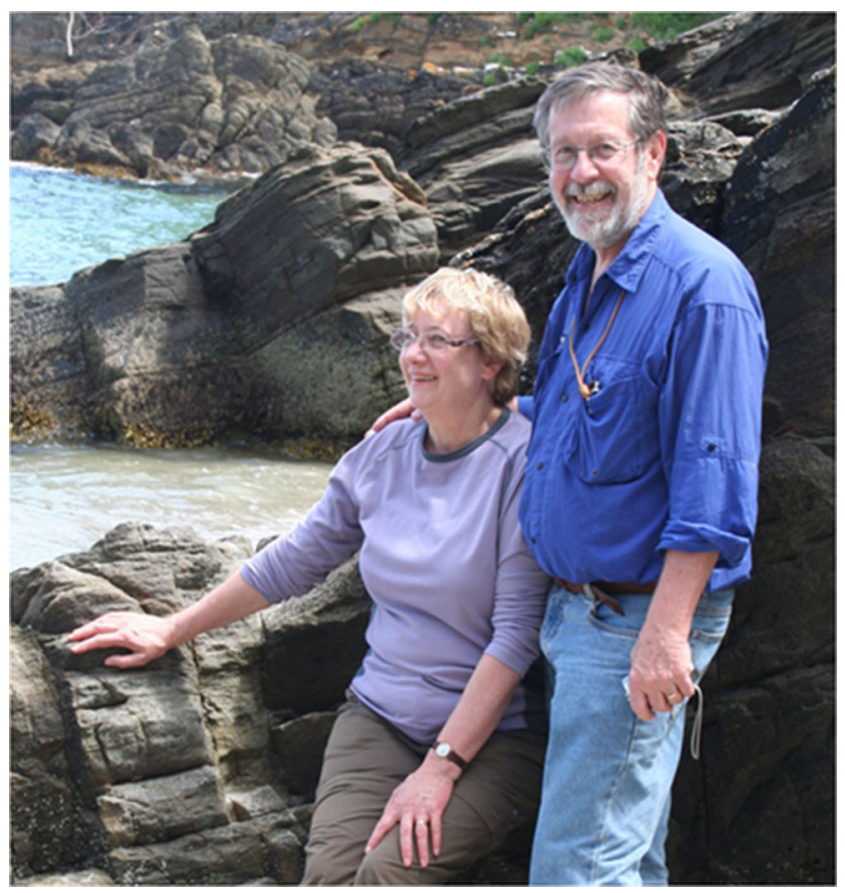

Sue and Bill in 2007, during fieldwork on eclogites in Brittany (photo: Norman Pearson)

One can wonder whether Sue O'Reilly subliminally imbued into the mind of Bill Griffin the key values from her secondary education at Goulburn High School, namely Respect, Responsibility and Resilience. But once

Jeff W. Harris

Jeff.Harris@glasgow.ac.uk

1 School of Geographical and Earth Sciences, University of Glasgow, Glasgow G12 8QQ, UK

2 Institut für Geowissenschaften, Petrologie und Geochemie, Goethe-Universität Frankfurt, Altenhöferallee 1, 60438 Frankfurt am Main, Germany those values became established, a formidable scientific team was born. While both play equally important scientific roles, the managerial skills of Sue are complemented by the experimental and analytical skills of Bill. And so it has been for over 30 years.

Their respect in scientific circles can be measured by their citation index which stands at over 89,000 and their h-index a measure of both productivity and citation impact - which stands at over 210 (Google Scholar 18/4/18). They have made transformative contributions to the study of the lithospheric mantle through the development of "4-dimensional geochemical tomography" and were among the first to integrate geochemical-petrologic tools with geophysical observables and numerical models for a holistic view of the continents through time. Their quest for innovative analytical techniques, such as the creation of single-crystal geothermometers or in situ analysis of trace elements in diamond, not only had huge impact on the scientific community but also revolutionised how industry is exploring for and tracing diamonds today. In addition and as an example, both are Distinguished Professors, and Sue also holds Professorships at two Universities in China as well as an Order of Australia Medal. Their scientific responsibility is seriously impressive, Sue being also the Director of a major Australian Research Council funded programme called the Centre of Excellence for Core to Crust Fluid Systems, which incorporates an earlier massive programme involving Geochemical Evolution and Metallogeny of Continents (GEMOC). Such programmes require analytical machinery and their maintenance and this is mostly Bill's side of the operation. At present, more than 90 postgraduate students and over 50 early career researchers have passed through these research programmes. As far as resilience is concerned, Sue and Bill are both past retirement age, but give little impression of slowing down. Perhaps their serious interest in wine, their conviviality and general joie de vivre are the non-scientific driving forces.

Publisher's Note Springer Nature remains neutral with regard to jurisdictional claims in published maps and institutional affiliations. 
It seems appropriate to finish this dedication with reference to a piece of poetry. In 'Ozymandias', by Shelley, an all-conquering army comes across a vast ancient and naturally ruined city where there is a stone plaque on which is written, 'Look on my works, ye Mighty, and despair'. Sue and Bills contribution to our un- derstanding of Earth's crust and mantle is profound and it is most worthy that a volume on the 11th Kimberlite Conference is named after them.

Jeff Harris and Sonja Aulbach

Edinburgh and Frankfurt, April 2018 